\title{
A Markowitz Approach For Asset Allocation In The Albanian Bond Market
}

\author{
Ardi Bezo, PhD Candidate \\ Profesional Business Academy, Tirana, Albania \\ Hidajet Shehu, Prof. PhD \\ Agricultural University of Tirana, Albania \\ Zamir Manaj, CFA, \\ San Paolo Bank of Tirana, Albania
}

doi: 10.19044/esj.2016.v12n10p129 URL:http://dx.doi.org/10.19044/esj.2016.v12n10p129

\begin{abstract}
Having reviewed all the components that meet a country's financial system, the Albanian financial market landscape is asymmetrical. To date investments in Albania are realized mainly through bank deposits or securities in informal way or Bonds investments. However, a high proportion of the total assets of life insurance companies are invested in deposits of commercial banks, it is necessary to diversify the sources of investments and a weakening dependence on commercial banks. This restructuring will bring changes in investment policy and in the risk management philosophy. The analytical approach consists in how to diversificate the risk throwing Optimization portfolio of all markets actors, detailed analysis of all the limitations that offers the Albanian financial market, identifying financial instruments comprising the investment portfolio of financial institutions and building a model optimization which will bring increased value of investments. At the end of the paper will be conducted a comparative analysis in Albania Financial markets.
\end{abstract}

Keywords: Diversification, Optimization Portfolio, Albanian Bills\&Bonds securities, Markowitz”s Optimization Model, Financial system.

\section{Introduction}

Fifty years have passed since the publication of Harry Markowitz's article on portfolio selection, setting forth the ground-breaking concepts that have come to form the foundation of what is now popularly referred to as Modern Portfolio Theory (MPT). 
The Modern Portfolio Theory is more than 60 years old. Among this corpus, the most practically relevant part is the Markowitz theory of Portfolio Selection.

The theory focuses on analyzing a portfolio in terms of the first 2 moments of the distribution of the returns of the assets in it and the correlations among them. A portfolio, in this context, is called efficient if it has the smallest possible variance among the portfolios with same return or conversely has the largest return among the portfolios with the same variance. The set of these portfolios is called the efficient frontier. According to the theory, the investor should focus on this set when she performs asset allocation of wealth.

The theory is highly mathematical, but has some intuitive appeal. Diversification, which is thought to be the main intuition in the theory, warns investors from concentrating their wealth in a certain asset or security. Investing, in fact, is not like entrepreneurship, you should not place all eggs in the same basket.

The theory has been criticized for being very mechanical, and sometime its output, especially when assets in the portfolio have high correlations, tends to produce portfolios which are not diversified but concentrated in the historically best assets. Furthermore, the theory in its original version, allowed short selling, which could be restricted and very risky to the average investor.

In spite of criticism, the theory remains one of the backbones of Modern Finance.

The theory and its improvements (like Black Litterman, 1992) have been largely used for allocating assets among stocks and indexes.

Its usage for allocation of assets among bonds has been limited on the past, because this market has been developed later.

This study goal is threefold, first it analysis the Albanian financial Market from the perspective of a wealth manager of private or institutional clients. Secondly, it applies the Markowitz theory to assets available in the Albanian market. The result of the analysis have been used to draw some conclusions for the financial advisors and clients who aim to invest in the Albanian Financial Market.

\section{Financial market in Albania}

Although in Albania reforms of the free market are dated back to the nineties, the financial market is in incubation phase. The country went on a deep crisis due to Ponzi schemes in the late nineties, which made people not confident in investing their money.

Although the banking system has existed from the time of the Ottoman Empire and continued to be consolidated in time when the Albanian 
state was created, it commenced to work properly and with a full set of services from the years 2000. Currently, there are 16 banks. Investment companies are rare. The main market is FOREX, but the exchanges are mainly spot.

From the perspective of a wealth manager or financial advisor, the so called opportunity set is very limited and possibility to diversify restricted. On the other side, there are even low possibilities in creating alpha, as there are limited resources for leveraging investments or concentrating the portfolio to alternative investments (a part from real estate which is ubiquitous).

The allocation of funds is done through private placement and mainly banks which take as deposits the largest part of savings.

There is no functional regulated market for trading equities (a Stock Exchange closed recently due to the lack of activity, as well as due to the lack of knowledge based on). Transfers are made through private contracts of which little or no available data exists. In any case, investors rarely hold equities in their portfolio as a tool for diversification. Stocks are generally held as a controlling or influencing share with the purpose to influence the decision of companies, i.e stockholders are almost surely entrepreneurs not investors.

In this situation, there are no Stock or other Indexes that track market transactions.

The principal investment products are government securities. (Some corporate bonds are present in the market, but this are in general privately held and not publicly traded).

There are also some mutual funds, but which themselves invest in government securities as do pension funds too.

The government raises money through bills and bonds of different maturities. The most widely used are 1 year bills, but there are regular auctions also for other maturities of the bills (discount instruments) of 3 months, 6 months and bonds 2 years, 5 years, 7 years and 10 years.

The bonds are with regular 6 month coupons either variable or fixed.

A very liquid secondary market exists for bills and short term bonds till 5 years of maturity. For longer term bonds the market is less liquid (in fact this bonds are usually held to maturity). In any case, this market is not regulated and transactions take place between banks or between banks and their clients. The primary market (Government auctions) is larger than the secondary one. 


\section{The data}

In this work, we have applied the Markowitz theory of diversification to the securities present in the Albanian market. In our knowledge, this work is the first in this ground.

Usually bonds are treated as a not risky asset. The greatest risk found in bonds is the duration risk, i.e the risk of parallel movements in the yield curve.

In this work, we take a different approach; we treat the government securities as a risky (volatile) asset and find the portfolio of this asset which minimizes their standard deviation given a required return.

We initially used bonds and bills of all maturities in our analysis. Given the non liquidity and the scarce trading in financial markets, we exclude the bonds of 7 years maturity and higher. Three month bills are excluded also, due to their ratio of risk and return.

We make our analysis based on the following assets:

- 6 month bills

- 12 year bills

- 2 years bonds

- 5 years bonds,

We used the time series of their yields from March 2009 to end year 2015. The data are monthly and refer to the end of month. Yields are calculated on a yearly basis. We have 82 point data for each asset having a reasonable amount of time series to make the model significant.

Generally, in Markowitz model estimation we need to have historical data which represent a full cycle of economic developments. In the set of data available, we have both the economic boom of 2009 and the fall of 2013 and the somewhat current stagflation that is characterizing the Albanian economy. In our estimation, a longer time series, would add little to the analysis.

\section{The model} 1952)

We use the standard Markowitz model in our analysis (Markowitz,

Let $\mathrm{R}$ be a random vector of returns. There are $\mathrm{N}$ assets which represent the opportunity set. These assets returns are represented as random variables on a finite probability set. These represent the yields of the bonds under analysis.

Let $\bar{R}$ be the vector of expected values of $\mathrm{R}$, i.e a vector which elements are all expected values of the yields under analysis.

Let SIG be the vector of standard deviations of $\mathrm{R}$ and let $\mathrm{W}$ be the vector of portfolio weights. 
We define a new vector $\mathrm{X}=\mathrm{SIG} * \mathrm{~W}$ as the vector which elements are the multiplication of elements of vectors SIG and W. Note that this is not the multiplication of vectors SIG and W which cannot be multiplied. Let [COR] be the correlation matrix of $\mathrm{R}$.

The portfolio return is defined as:

$$
P R=W^{\prime} \bar{R}
$$

Where $W^{\prime}$ is the transpose of $W$ (where not specified a vector means a column vector).

The portfolio standard deviation is defined as:

$$
P S=X^{\prime}[C O R] X
$$

Where $X^{\prime}$ is the transpose of $X$.

The Markowitz algorithm is the following:

Under the constrains

$$
\{M I N[P S]\}_{W}
$$

$$
\left\{\begin{array}{c}
W^{\prime} I=1 \\
\forall w \in W, w>0 \\
P R=R R
\end{array}\right\}
$$

Where I will be the unitary vector and RR is the required return.

Notice that we ruled out short selling as this is not a practice in the Albanian market. (Short selling operations are almost impossible as there is no financial law to support them and there are not intermediaries who offer this service).

The same result can be achieved by maximizing the return PR with the same set of constraints but maintaining the standard deviation constant at a required value.

In running the model, we had to estimate have estimated $\bar{R}$, SIG and $[C O R]$.

We used the historical method to estimate these input. That means using time series and applying the historical estimators of mean and variance. This is a somewhat classical approach, but not the only one.

\section{The results}

In our estimation of the input vectors, we came out with the following results,

\begin{tabular}{|cccccc|}
\hline \multicolumn{7}{c}{ Treasury securities portfolio } & & \\
\hline Product & $\mathbf{6 M}$ & $\mathbf{1 2 M}$ & $\mathbf{2 ~ V}$ & $\mathbf{5}$ V & Portfolio \\
\hline Expected Return & $5.48 \%$ & $6.12 \%$ & $7.15 \%$ & $8.14 \%$ & $6.72 \%$ \\
\hline Standard Deviation & $1.76 \%$ & $2.19 \%$ & $1.84 \%$ & $1.82 \%$ & $1.89 \%$ \\
\hline
\end{tabular}

As it can easily be noticed, according to mean variance theory, 12 months treasuries and 2 year bonds are dominated by the other 2 securities. We demonstrate later that these securities do not add diversification to the 
portfolio. (The ruling out of short sales gives surprising results, as the algorithm focuses only on the best securities in terms of mean and variance. With short sales less efficient securities could be sold short in order to buy more of the efficient ones).

The correlation matrix estimated based on the data is the following

\begin{tabular}{|ccccc|} 
& $\mathbf{6 M}$ & $\mathbf{1 2 M}$ & $\mathbf{2} \boldsymbol{V}$ & $\mathbf{5} \boldsymbol{V}$ \\
\hline $\mathbf{6 M}$ & 1 & 0.989627 & 0.976547 & 0.959635 \\
\hline $\mathbf{1 2 M}$ & 0.989627 & 1 & 0.985352 & 0.973547 \\
\hline $\mathbf{2} \boldsymbol{V}$ & 0.976547 & 0.985352 & 1 & 0.971229 \\
\hline $\mathbf{5} \boldsymbol{V}$ & 0.959635 & 0.973547 & 0.971229 & 1 \\
\hline
\end{tabular}

As noted, government securities are highly correlated among them, despite this there is still possibility for diversification as we will demonstrate shortly (although not a standard type of diversification). Government securities high correlations are due to the Central Bank intervention in the market to control yields. Unlike equities, the bond market is not really a free market.

Using the above algorithm, we arrive at the following efficient set.

\begin{tabular}{|cccccc|}
\hline & & \multicolumn{5}{c|}{ WEIGHTS } \\
\hline Portfolio return & Portfolio risk & $\mathbf{6 M}$ & $\mathbf{1 2 M}$ & $\mathbf{2 ~ V}$ & $\mathbf{5 ~ V}$ \\
\hline $5.5 \%$ & $1.756 \%$ & $100 \%$ & $0 \%$ & $0 \%$ & $0 \%$ \\
\hline $6.0 \%$ & $1.758 \%$ & $81 \%$ & $0 \%$ & $0 \%$ & $19 \%$ \\
\hline $6.5 \%$ & $1.765 \%$ & $62 \%$ & $0 \%$ & $0 \%$ & $38 \%$ \\
\hline $7.0 \%$ & $1.777 \%$ & $43 \%$ & $0 \%$ & $0 \%$ & $57 \%$ \\
\hline $7.5 \%$ & $1.795 \%$ & $24 \%$ & $0 \%$ & $0 \%$ & $76 \%$ \\
\hline $8.0 \%$ & $1.817 \%$ & $5 \%$ & $0 \%$ & $0 \%$ & $95 \%$ \\
\hline $8.1 \%$ & $1.824 \%$ & $0 \%$ & $0 \%$ & $0 \%$ & $100 \%$ \\
\hline
\end{tabular}

Notice that the efficient set starts from the return achieved by investing ones wealth $100 \%$ on the instrument with the lowest risk, the 6 months bills end finishes with return achieved by investing $100 \%$ in the instrument with the highest return.

The following charter illustrates graphically the efficient frontier created. The shape is similar to a standard efficient frontier, but the fact that there are no short sales make it smoother. 


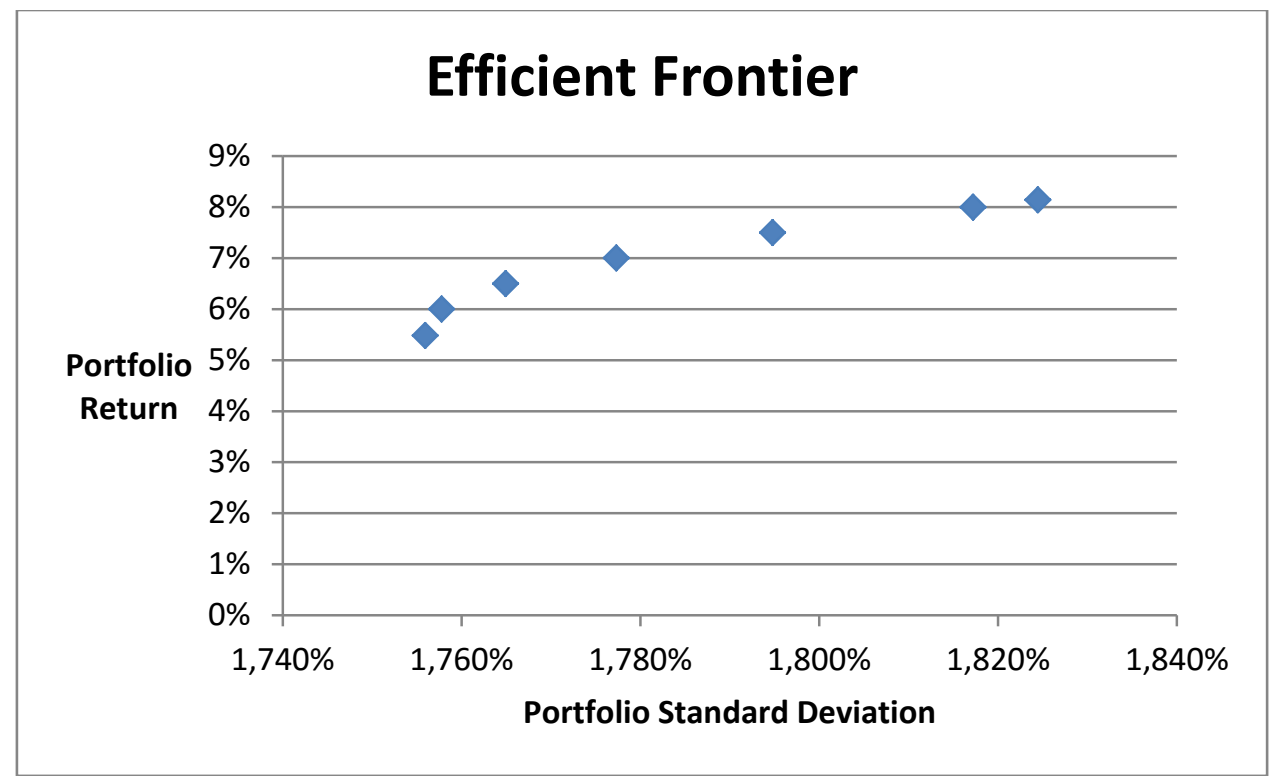

The ruling out of short selling makes that the efficient set be very restricted. We tried the same approach with short selling and the results were not surprisingly different.

We notice that some assets are excluded from the efficient set. This was obvious from the beginning, as the 12 months bills and 2 years bonds were dominated respectively by 6 month bills and 5 year bonds.

To prove that diversification adds value in terms of optimization of risk and return, we constructed a frontier based on a naïve diversification, i.e diversification based only on the return target. The investor combines assets in order to arrive at a specified required return.

The following frontier came out.

Non Efficient frontier (Naive)

\section{Weights}

\begin{tabular}{|cccccc|}
\hline Portfolio Return & Portfolio Risk & $\mathbf{6 M}$ & $\mathbf{1 2 M}$ & $\mathbf{2 ~ V}$ & $\mathbf{5} \mathbf{~ V}$ \\
\hline $\mathbf{5 , 4 8 \%}$ & $1,760 \%$ & $100 \%$ & $0 \%$ & $0 \%$ & $0 \%$ \\
\hline $\mathbf{6 , 0 0 \%}$ & $1,774 \%$ & $75 \%$ & $3 \%$ & $8 \%$ & $13 \%$ \\
\hline $\mathbf{6 , 5 0 \%}$ & $1,797 \%$ & $51 \%$ & $6 \%$ & $17 \%$ & $26 \%$ \\
\hline $\mathbf{7 , 0 0 \%}$ & $1,825 \%$ & $27 \%$ & $9 \%$ & $25 \%$ & $39 \%$ \\
\hline $\mathbf{7 , 5 0 \%}$ & $1,857 \%$ & $2 \%$ & $12 \%$ & $33 \%$ & $52 \%$ \\
\hline $\mathbf{8 , 0 0} \%$ & $1,820 \%$ & $0,000 \%$ & $0 \%$ & $14 \%$ & $86 \%$ \\
\hline $\mathbf{8 , 1 4} \%$ & $1,824 \%$ & $0 \%$ & $0 \%$ & $0 \%$ & $100 \%$ \\
\hline
\end{tabular}

As seen for the same value of required return the naïve frontier has higher level of risk compared to the efficient frontier. 


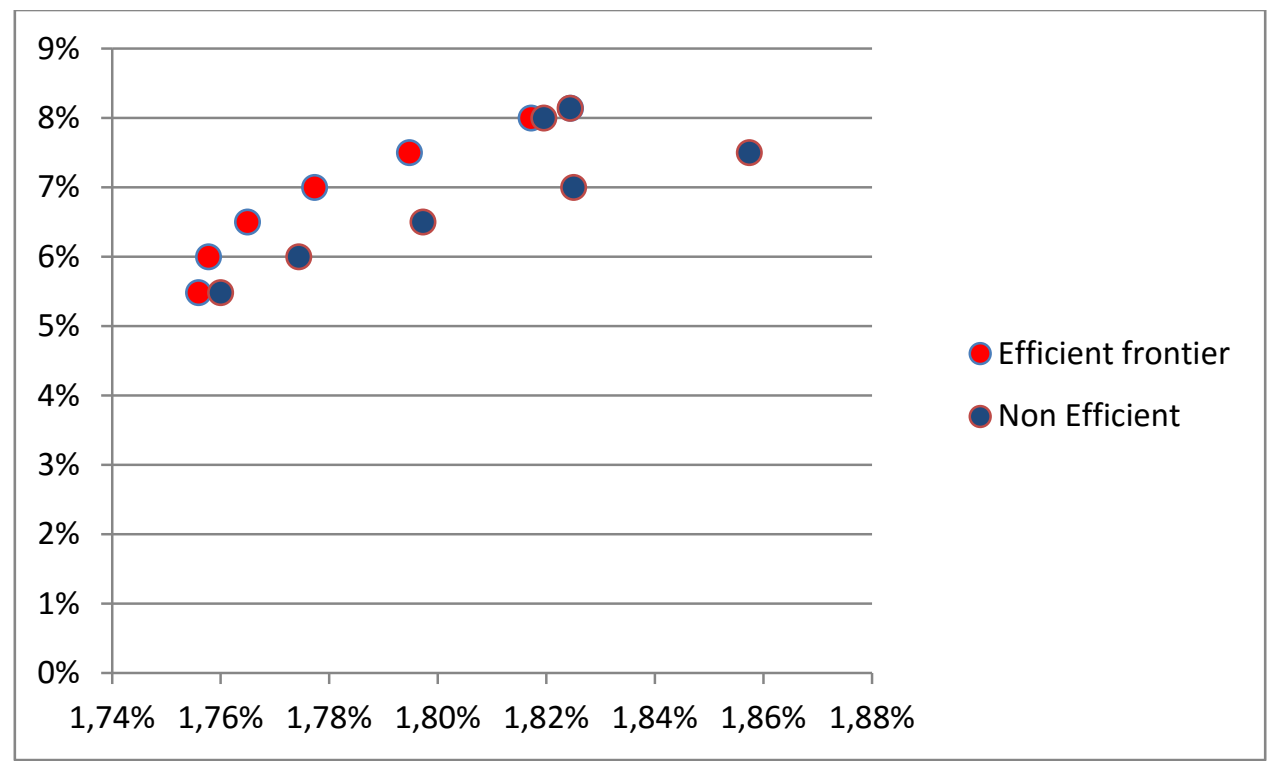

Notice however that the 2 frontiers intersect in the so called minimum variance portfolio, the one fully invested in the 6 months product and the highest return portfolio, that which is fully invested in the 5 years bond.

\section{Limits of the above analysis}

In this study, we consider bonds as risky assets and base allocation on them on expected return (yield) and standard deviation of the yields. This is usually an uncommon approach for bonds, although it is perfectly meaningful in the situation of the Albanian market where the investment opportunity set is limited. However, we understand that our analysis has some limits which we list below:

- $\quad$ In our analysis, we considered the volatility of yields directly. Given that the securities are exchanged between banks and between banks and their clients, we do not have the time series of prices. This is a major limit, as yields which are publicly disclosed depend mainly on Government Auctions (This is the classical situation when we infer the secondary market from the data available from the primary market).

- The main risk of government securities is that of default. The Government can default at any time on payments of bonds due to high debt and mismanagement of public finance. This risk is not, however, completely reflected in the volatility of their yields. Yield movement is biased by the interventions of Central Bank Monetary Policy. A movement in yields does not necessary mean a change in the default risk of bonds. 
- $\quad$ The third limit is related to the second one. High volatility of the yields does not necessary mean that the bonds are more risky. Volatility could be only downside and mean that the Government is entering a process of reforms in its budget management which allow it to raise money with a lower rate.

Despite the above limits, our analysis above shows that the Markowitz model can be used to allocate wealth among bonds.

\section{Conclusion}

In our conclusion, with short selling ruled out, the 12 month bills and 2 year bonds are instruments which, besides being not efficient, do not add diversification to the portfolio.

An investor should avoid investing in these instruments and should create its portfolio based on the 6 months bills and 5 year bonds instead.

Decision makers and their financial advisors should base their asset allocation directly on this efficient frontier. In our view, creating a Security Market Line in this framework would be inappropriate. Notice, however, that in this particular case a combination of the 2 chosen assets (the 6 month bill and the 5 year bond) could be appropriate as an approximate to the mean variance efficient frontier. However, this conclusion is consequence of the optimization framework we used.

\section{Consequences for Portfolio Management of private and institutional portfolios}

Financial advisors and clients who aim to invest in the Albanian market have a very limited set of choices to the state of the development of the market. Nevertheless, they should continue to follow the general rules for a proper portfolio management.

The advisor must set a standard Investment Policy Statement which should contain at least the following elements:

\section{Risk and Return Objectives}

In setting the objectives in terms of risk and return, the financial advisor must consider the particular circumstances of the market (Capital Market Expectations).

The return must be appropriate in order to meet the client's objectives, but first the risk considerations must be made, in order to not let the portfolio have major variations.

\section{Constrains}

Liquidity can be major concern given the absence of a regulated market in Albania. 
Legal and Regulatory constrains are generally not a concern, although the regulatory framework is changing fast.

Tax constrains is less relevant as generally all financial incomes are taxed at a flat rate.

Time horizon is an important concern. Short term horizon investors could be more confident with bills, given the scarce secondary market of the bonds, especially in the longer term edge.

Unique constrains could be specific to some investors, but generally common unique constrains are generally not present in the market.

Our model advises that the investor must allocate her wealth on 6 month bills and 2 year bonds. Its allocation would depend on the Investor Policy Statement objectives on return and risk.

The set of solutions is illustrated in the following graph.

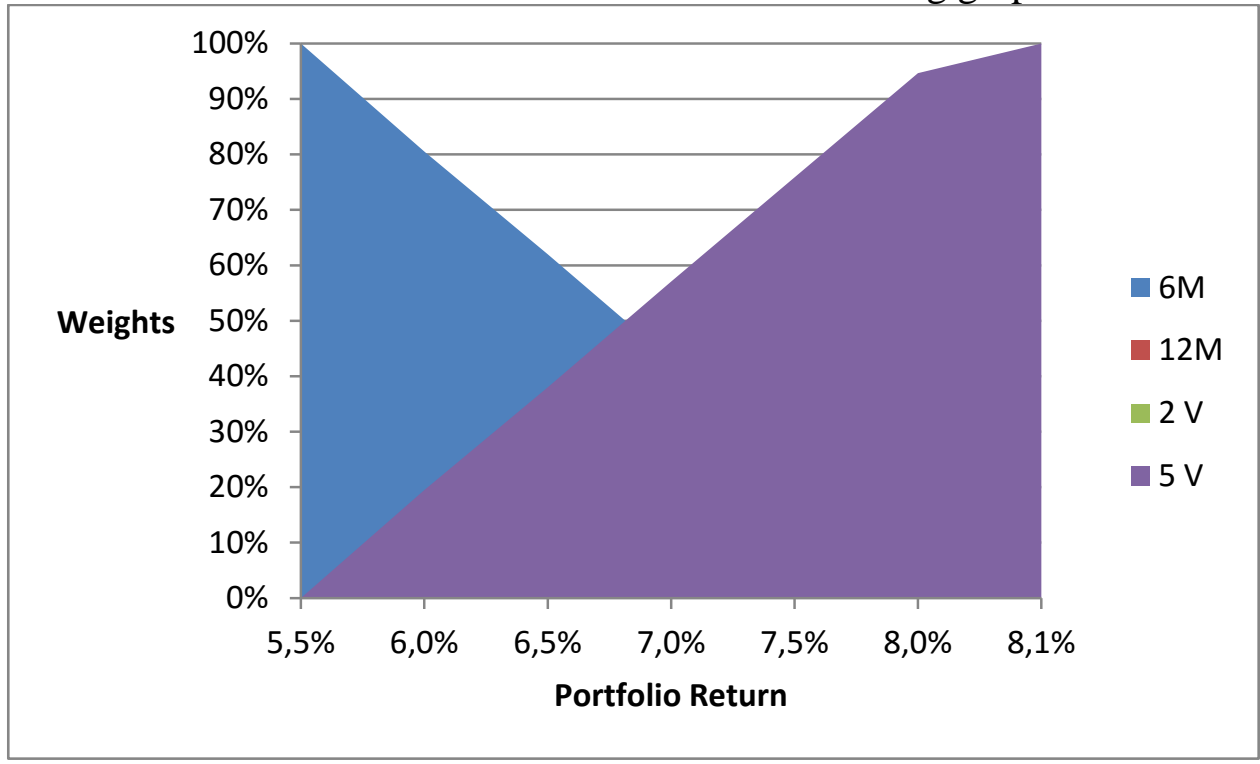

Here it is shown allocation based on different required returns. If the investor has a moderate return objective (and consequently low risk profile) she could base her choice on the left hand side allocation solution, allocating her wealth more on 6 month bills. Increasing its return objectives and risk appetite, the investor can shift its choice by buying more of the 5 year bond.

Obviously, other constrains may be considered like liquidity which could further impact the solution. The Markowitz approach is based only on risk and return objectives without considering all constrains of an Investment Policy Statement.

Liquidity constrain could be an issue in the Albanian market. Not always it is possible to find a counterparty which is available to liquidate the assets in your portfolio, although there are in general transactions on these 
assets. Liquidity of bonds is a major problem than that of the bills. Even if a party is found, it could require a premium for liquidating the asset (a discount from the perspective of the investor). Such costs may impact the effective yield, i.e the yield effectively received by the investor and change the overall mean variance analysis.

Optimizing with liquidity constrains could be other results not compatible with the Markowitz model.

The other constrains (Legal, Tax, Time horizon and Unique) are less important in general, but should in any case taken care of by financial advisors when they consult and act on behalf of their client on the portfolios.

\section{References:}

Markowitz, H. (1952), Portfolio Selection, Journal of Finance. 6(1952): 7791.

Markowitz, H. (1952). "The Utility of Wealth". The Journal of Political Economy (Cowles Foundation Paper 57) LX (2): 151-158.

Markowitz, H. (2009). Harry Markowitz: Selected Works. World ScientificNobel Laureate Series: Vol. 1. Hackensack, New Jersey: World Scientific. pp. 716. ISBN 978-981-283-364-8.

Sharpe (1964). Capital asset prices: A theory of market equilibrium under conditions of risk. J. of Finance 19 (3) 425-442.

Mikkel Rasmussen (2003). Quantitative Portfolio Optimization, Asset Allocation and Risk Management: A Practical Guide to Implementing Quantitative Investment Theory. Palgrave Macmillan, 2003. Palgrave Connect. Palgrave Macmillan. 13 Oct 2012, http://www.palgrave connect. com/pc/doifinder/10.1057/9780230512856.

Sharpe (1967). "A Linear Programming Algorithm for Mutual Fund Portfolio Selection," Management Science, INFORMS, vol. 13(7), pages 499-510, March.

Sharpe (1967). "Portfolio Analysis," Journal of Financial and Quantitative Analysis, Cambridge University Press, vol. 2(02), pages 76-84, June.

Frank J. Fabozzi, Francis Gupta, and Harry M. Markowitz, The Legacy of Modern Portfolio Theory. 